\title{
Detection of antibodies against the CB9 to ICB10 region of merozoite surface protein- 1 of Plasmodium vivax among the inhabitants in epidemic areas
}

\author{
Tong-Soo Kim ${ }^{1 \dagger}$, Youngjoo Sohn ${ }^{2 \dagger}$, Jung-Yeon Kim ${ }^{3}$, Won-Ja Lee ${ }^{3}$, Byoung-kuk Na ${ }^{4}$, Yoon-Joong Kang ${ }^{5^{*}}$ \\ and Hyeong-Woo Lee 6* $^{*}$
}

\begin{abstract}
Background: The purpose of this study was to examine the usefulness of the conserved block 9 (CB9) to interspecies conserved block (ICB10) region of Plasmodium vivax merozoite surface protein-1 (MSP-1 (ICB910)) as a serodiagnostic tool for understanding malaria transmission.

Methods: Antibody titre in the blood samples collected from the inhabitants of Gimpo city, Paju city and Yeoncheon county of Gyeonggi Province, as well as Cheorwon county of Gangwon Province, South Korea were determined by enzyme-linked immunosorbent assay (ELISA). Microscopic examination was performed to identify malarial parasites.

Results: MSP-1(ICB910) is encoded by a 1,212-bp sequence, which produced a recombinant protein with a molecular weight of approximately $46 \mathrm{kDa}$. Antibody titres in 1,774 blood samples were determined with the help of ELISA using purified recombinant MSP-1(ICB910). The overall ELISA-positive rate was $8.08 \%(n=146)$. The annual parasite incidences (APIs) in the regions where the blood sampling was carried out gradually decreased from 2004 to 2005 (1.09 and 0.80, respectively). Yeoncheon county had the highest ELISA-positive rate $(10.20 \%, 46 / 451)$. Yeoncheon county also had the highest API both in 2004 and 2005, followed by Cheorwon county, Paju city and Gimpo city.

Conclusions: The MSP-1 (ICB910)-ELISA-positive rates were closely related to API in the geographic areas studied. These results suggest that sero-epidemiological studies employing MSP-1 (ICB910)-ELISA may be helpful in estimating the prevalence of malaria in certain geographic areas. MSP-1(ICB910)-ELISA can be effectively used to establish and evaluate malaria control and eradication programmes in the affected areas.
\end{abstract}

\section{Background}

Plasmodium vivax causes the relapse of benign tertian human malaria that affects several hundred millions of individuals annually. This disease is a major public health concern in most tropical and many temperate regions, including North and South Korea [1]. The first scientific documentation of malaria occurrence was published in 1913 [2]. A national malaria eradication programme

\footnotetext{
* Correspondence: yjkang@jwu.ac.kr; rainlee67@naver.com

${ }^{\dagger}$ Equal contributors

${ }^{5}$ Department of Biomedical Science, Jungwon University, Goesan, Chungbuk 367-805, Republic of Korea

${ }^{6}$ Department of Pathology, Immunology, and Laboratory Medicine, College of Medicine, University of Florida, Florida, FL 32610, USA

Full list of author information is available at the end of the article
}

strengthened by the involvement of the World Health Organization has succeeded in significantly reducing the incidence of malaria in South Korea [3,4]. Malaria was thought to have been eradicated in South Korea in the late 1970s until two sporadic cases were detected in the 1980s [5]. In 1993, a case was diagnosed among South Korean soldiers serving in Northern Gyeonggi Province [6]. Subsequently, Cho et al. reported two instances of infected civilians [7]. Thereafter, many new cases have been reported near the demilitarized zone (DMZ): in Paju, Yeoncheon, Cheorwon, Gimpo, Ganghwa, Goyang, and Dongducheon. The increasing number of new cases raises the concern that malaria will become re-established in the region $[8,9]$.

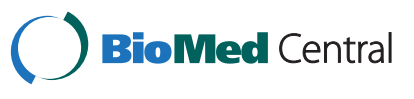

(C) 2014 Kim et al.; licensee BioMed Central Ltd. This is an Open Access article distributed under the terms of the Creative Commons Attribution License (http://creativecommons.org/licenses/by/4.0), which permits unrestricted use, distribution, and reproduction in any medium, provided the original work is properly credited. The Creative Commons Public Domain Dedication waiver (http://creativecommons.org/publicdomain/zero/1.0/) applies to the data made available in this article, unless otherwise stated. 
The malaria research team of the Korea National Institute of Health (KNIH) has developed a new diagnostic method to support pathological examinations. This antibodybased detection method uses merozoite surface protein-1 (MSP-1), an antigen and a large (180-230 kDa) glycoprotein that is synthesized as a precursor to MSP during schizogony [10]. Comparisons of the sequences of MSP-1 from Plasmodium vivax, Plasmodium falciparum and Plasmodium yoelii revealed the existence of ten interspecies conserved blocks (ICBs) containing eight polymorphic regions [11]. Serological surveys have provided valuable epidemiological information, particularly in the areas of low endemicity [12]. Estimation of the rate of parasitaemia is the classical method of measuring the prevalence of malaria. However, the incidence of parasitaemia alone may fail to adequately describe the epidemiology of malaria within a given population. For instance, when the incidence of malaria is low, mass blood surveys do not yield results commensurate with the work involved $[13,14]$. In this study, the anti-P. vivax MSP-1 antibody levels (particularly against the CB9 to ICB10 region) among the populations of Gimpo, Paju, Yeoncheon, and Cheorwon were determined to evaluate the usefulness of the recombinant MSP-1(ICB910) antigen for assessing the local malaria prevalence.

\section{Methods}

\section{Blood samples of inhabitants}

To evaluate the usefulness of the recombinant MSP-1 (ICB910) protein in serodiagnosis, blood samples were obtained from the KNIH of the Korean Center for Disease Control and Prevention (KCDC). These blood samples (from 1,774 individuals) were collected from Gimpo and Paju cities, Yeoncheon county of Gyeonggi Province, and Cheorwon of Gangwon Province of South Korea, from November to December of 2004 (Figure 1), and were stored at the KNIH. Blood smears were also obtained from the KNIH for microscopic examination.

\section{Ethics statement}

This study was conducted after receiving the written informed consent from all participants and only after receiving approval from the KNIH. The study procedures, potential risks and benefits were explained to all of them. Further, all data were analysed anonymously and patients were not identified by name. This study was conducted strictly adhering to the principles expressed in the Declaration of Helsinki.

\section{Microscopic examination}

Thin blood films were prepared to determine the infectivity of blood samples. The blood films were fixed with methanol and stained with Giemsa stain to reveal the parasite inclusions in the red blood cells (RBCs). Thin blood films are often preferred for routine estimation of parasitaemia because the organisms can be readily visualized and quantified with this method [15]. To estimate the densities of blood-stage parasites by microscopy, the number of asexual parasites observed per 200 white blood cells (WBCs) was determined, which was then multiplied by the assumed number of WBCs per microlitre of blood $(8,000)$ [16].

\section{Amplification of the MSP-1 gene}

To express the CB9 to ICB10 region of the $P$. vivax MSP-1 gene, genomic DNA was extracted from the whole blood of a patient diagnosed with malaria using a QIAamp Blood Kit (Qiagen, Hilden, Germany). The polymerase chain reaction (PCR) mixture contained AccuPower PCR PreMix (Bioneer, Daejeon, Korea), 50 ng of purified genomic DNA, and 40 pmoles each of forward (MSP-910 F; 5' -ggatccGAAGACCAAGTAACAACGGG AGAG-3') and reverse (MSP-910R; 5' -aagcttTTAAAGCT CCATGCACAGGAG-3') primer (Figure 2). The total volume of the reaction mixture was adjusted to $50 \mu \mathrm{L}$ with distilled water. The thermal cycling conditions were as follows: denaturation at $94^{\circ} \mathrm{C}$ for $5 \mathrm{~min}$; 35 cycles of $30 \mathrm{sec}$ at $94^{\circ} \mathrm{C}, 60 \mathrm{sec}$ at $55^{\circ} \mathrm{C}$, and $45 \mathrm{sec}$ at $72^{\circ} \mathrm{C}$; and a final incubation at $72^{\circ} \mathrm{C}$ for $5 \mathrm{~min}$. All PCR products were analysed by agarose gel electrophoresis on a $1 \%$ agarose gel, visualized under an ultraviolet transilluminator, and purified using a NucleoSpin Extract Kit (Macherey-Nagel; Duren, Germany).

\section{DNA sequencing and analysis}

To genotype the MSP-1(ICB910) gene of $P$. vivax, the MSP-1(ICB910) gene was PCR-amplified and ligated into a pCR2.1 vector (Invitrogen, Carlsbad, CA, USA) and transformed into Escherichia coli TOP10 cells. The E. coli TOP10 cells containing the recombinant plasmid were selected in medium containing ampicillin [17]. Plasmids were purified using a Qiagen plasmid isolation kit according to the manufacturer's protocols. The transformants were confirmed by agarose gel electrophoresis following restriction digestion with EcoRI. The MSP-1(ICB910) gene sequence was determined using an ABI PRISM Dye Terminator Cycle Sequencing Ready Reaction Kit FS (Perkin Elmer, Cambridge, MA, USA) following manufacturer's instructions. M13 reverse and forward (-20) primers were used for sequencing. Nucleotide and deduced amino acid sequences were analysed using EditSeq and Clustal in the MegAlign program, a multiple alignment program within the DNASTAR package (DNASTAR, Madison, WI, USA). The internet-based BLAST search program of the National Center for Biotechnology Information was used to search protein databases. 
A

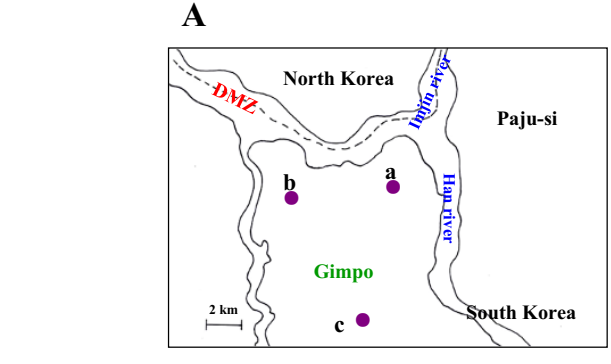

B

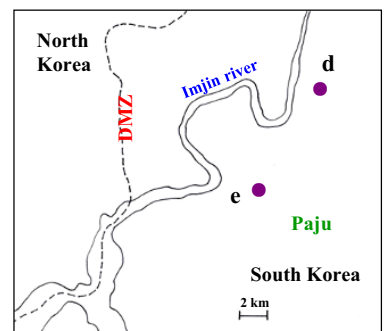

C

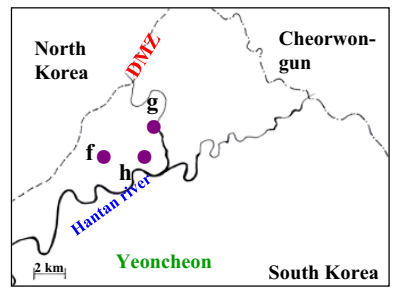

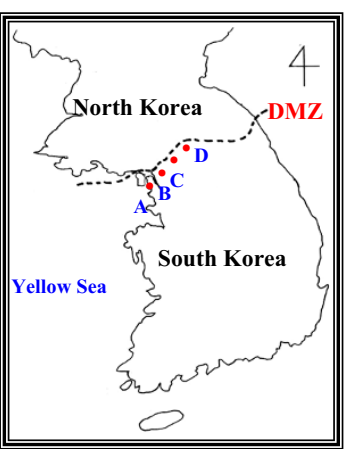

D

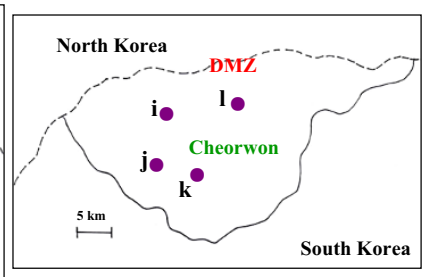

Figure 1 Blood sample collection areas according to administrative districts. (A) Gimpo, (B) Paju, (C) Yeoncheon, (D) Cheorwon. a, Haseongmyeon; b. Wolgotmyeon; c, Yangchonmyeon; d, Papyeongmyeon; e, Munsaneup; f, Baekhakmyeon; g, Wangjingmyeon; h, Misanmyeon; i, Gimhwaeup; j, Seomyeon; k, Cheorwoneup; I, Geunnammyeon.

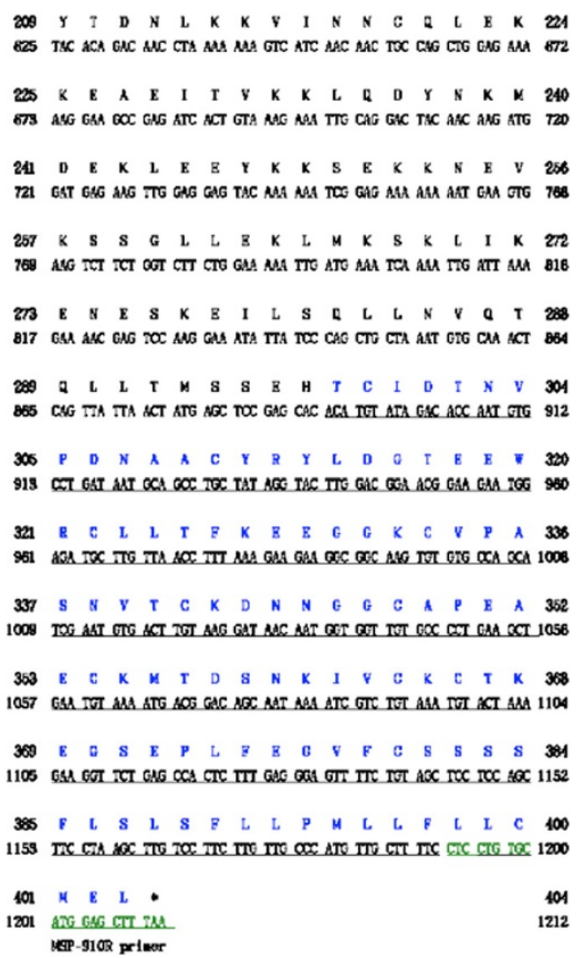

Figure 2 Nucleotide and amino acid sequences of Plasmodium vivax merozoite surface protein-1(ICB910). The nucleotide sequence was deposited in GenBank BLAST (http://WWW.ncbi.nlm.nih.gov/nuccore, Accession No. KJ513462). 


\section{Construction of the MSP-1(ICB910) expression vector}

To express the MSP-1 gene in E. coli DH5 $\alpha$ cells, the CB9 to ICB10 region of the MSP-1 gene fragment was amplified using MSP-910 F and MSP-910R primers (respectively containing BamHI and HindIII sites at their $5^{\prime}$ ends) from a blood sample that was confirmed to be infected with the dormant type of $P$. vivax (Figure 2). The amplified-PCR products were digested with BamHI and HindIII, the products were gel-purified using a Qiagen gel extraction kit, and were ligated between the BamHI and HindIII cleavage sites of the pQE30 expression vector (Qiagen). The resulting plasmid was used for the expression of a MSP-1(ICB910)-(His) ${ }_{6}$ fusion protein in $E$. coli cells. The transformants were first confirmed by agarose gel electrophoresis following restriction digestion using BamHI and HindIII. Finally, the insert sequence was confirmed by DNA sequencing.

\section{Expression and purification of recombinant MSP-1(ICB910)} The expression of the recombinant MSP-1(ICB910)-(His) 6 fusion protein in $E$. coli $\mathrm{DH} 5 \alpha$ cells was induced with isopropyl-1-thio- $\beta$-D-galactopyranoside (IPTG) [18]. The MSP-1(ICB910)-(His) ${ }_{6}$ fusion protein was purified using immobilized metal ion affinity chromatography [19] under native conditions following the manufacturer's protocols (Qiagen). Protein levels were analysed by sodium dodecyl sulphate-polyacrylamide gel electrophoresis (SDS-PAGE) after each purification step.

\section{Western blot analysis}

The recombinant MSP-1(ICB910)-(His) 6 fusion protein was separated by SDS-PAGE on a $12 \%$ gel and transferred onto a nitrocellulose membrane. After the transfer, the membrane was cut into strips and blocked for nonspecific binding with $3 \%$ skim milk for $12 \mathrm{hr}$ at $4{ }^{\circ} \mathrm{C}$. The membrane was then washed three times for $10 \mathrm{~min}$ each with 0.15\% Tween 20 in phosphate-buffered saline (PBS). Following this, the strips were allowed to react for $4 \mathrm{hr}$ with sera from patients with malaria or from uninfected individuals (diluted $1: 100$, vol $/ \mathrm{vol}$ ). The membranes were then washed three times for 10 min each with $0.15 \%$ Tween 20 in PBS and were subsequently incubated with peroxidaseconjugated goat anti-human IgG secondary antibody $(1: 1,000)$ (Sigma) for $3 \mathrm{hr}$ at room temperature. For colour development, a solution containing $0.2 \%$ diaminobenzidine and $0.02 \% \mathrm{H}_{2} \mathrm{O}_{2} / \mathrm{PBS}$ was applied to each well $[20,21]$.

\section{Enzyme-linked immunosorbent assay (ELISA)}

An ELISA was used to determine whether the blood samples contained antibodies against MSP-1(ICB910) antigens. Briefly, the capture antigen solution $(50 \mu \mathrm{L}$, $0.5 \mu \mathrm{g} / \mathrm{mL}$ ) was placed in a 96-well plate (Corning, Lowell, MA, USA) and incubated for $12 \mathrm{hr}$ at room temperature.
The antigen solution was then aspirated, blocking buffer (1\% bovine serum albumin, $0.05 \%$ PBS-Tween 20) was added to each well, and the plate was incubated for $1 \mathrm{hr}$ at room temperature. After the wells were washed three times with $0.05 \%$ Tween $20 / \mathrm{PBS}$, human serum samples in blocking buffer at a dilution of 1:100 ( $\mathrm{vol} / \mathrm{vol})$ were added to the wells. Four positive and four negative control serum samples were also included in each plate. After incubating at room temperature for $2 \mathrm{hr}$, the plates were washed with 0.05\% Tween 20/PBS three times. Peroxidase-conjugated anti-human IgG (Sigma, 1:2,000, vol/vol) diluted in blocking buffer was then added to each well and the plates were incubated for $1 \mathrm{hr}$ at room temperature. Following this, the reaction was stopped by washing the plates as described above. To develop the colour, $100 \mathrm{~mL}$ of 2,2'-azino-di-(3ethyl-benzthiozoline-6-sulphonic acid) (ABTS) peroxidase substrate (Kirkegaard \& Perry Laboratories, Gaithersburg, MD, USA) was added to each well and the plates were incubated for $30 \mathrm{~min}$. This was followed by measuring the absorbance of the solution at $405 \mathrm{~nm}$. Cut-off value for ELISA-positivity was defined as the sum total of the mean values and two times the standard deviations of the negative control samples.

\section{Estimation of the annual parasite incidence (API)}

For each of the study sites, the annual parasite incidence (API) was calculated as the number of malaria-positive patients per 1,000 inhabitants; API $=$ (number of positive slides/total number of slides) $\times 1,000$.

\section{Data analysis}

The data were analysed using Graphpad Prism software version 4.0 (GraphPad Software Inc., La Jolla, CA, USA). Pearson's correlation analysis was performed to examine the relationship between seropositivity and the API of $P$. vivax in a given year. The data were analysed using SPSS software, version 17.0 (SPSS Inc., Chicago, IL, USA). A $P$-value of $<0.05$ indicated statistical significance. The correlation sizes were interpreted as none (0.0-0.09), small (0.1-0.3), medium (0.3-0.5), or strong (0.5-1.0) [22].

\section{Results}

\section{Blood sampling}

The study locations are shown on the map in Figure 1. All areas were near the DMZ, a known high-risk area. Blood samples were collected from participants residing in 23 villages and three cities (Gimpo, Paju and Yeoncheon) located in Gyeonggi Province and six villages in Cheorwon of Gangwon Province, South Korea. A total of 1,774 blood samples (1.92\%) were collected. The total number of inhabitants in the geographical areas where the study was conducted in the year 2004 was 92,246. 


\section{DNA sequence of Plasmodium vivax MSP-1(ICB910) (Korean isolate)}

The region from CB9 to ICB10 of the MSP-1 gene that was PCR-amplified from the genomic DNA was analysed on a 1.0\% agarose gel. Amplification of the MSP-1(ICB910) gene yielded an approximately 1,200-bp DNA fragment that was then ligated to the pCR2.1 cloning vector. Restriction analysis using EcoRI confirmed the identity of the transformants. The plasmid containing the PCR product was named pMSP910 and was subjected to DNA sequence analysis. DNA sequencing revealed that the cloned MSP-1(ICB910) gene was 1,212-bp in length and encoded 403 amino acids as identified by DNASIS (Figure 2, Genbank accession No KJ513462).

\section{Expression of MSP-1(ICB910) in Escherichia coli and its antigenicity}

To construct the expression plasmid, the MSP-1(ICB910) gene was amplified from the patient's genomic DNA, digested with BamHI and HindIII, and subcloned into the same restriction enzyme sites of the pQE30 expression vector to produce pMSPex910 containing a (His) ${ }_{6}$-tag. The recombinant pMSPex910 plasmid was then transferred into $E$. coli DH5 $\alpha$ cells. For protein expression, $1 \mathrm{mM} \mathrm{IPTG}$ was added to E. coli DH5 $\alpha$ (pMSPex910) cells grown to logarithmic phase in liquid Luria-Bertani medium containing $100 \mu \mathrm{g} / \mathrm{mL}$ ampicillin and $50 \mu \mathrm{g} / \mathrm{mL}$ kanamycin to induce the expression. SDS-PAGE followed by Coomassie blue staining showed that under native purification conditions, the molecular weight of the recombinant MSP-1(ICB910) protein was $\sim 46 \mathrm{kDa}$ (Figure 3A). The antigenicity of the MSP-1(ICB910) recombinant protein was determined by Western blot. The sera from patients with malaria reacted positively (Figure $3 \mathrm{~B}$, No $1-3$ ). One sample (Figure 3B, No 6), which was collected from an individual who had no symptoms of infection, showed weak positivity. During the follow-up study, this case became ill four months after the blood sampling and was diagnosed with vivax infection. To determine the sensitivity and specificity of the MSP-1(ICB910) recombinant protein by ELISA, the sera of patients with malaria were used. Sera from 68 of the 70 patients with malaria (sensitivity, 97.1\%) were ELISA-positive, whereas all samples in the normal control group $(n=8)$ were ELISA-negative (specificity, 100\%) (Figure 3C).

\section{Overview of malaria transmission in four locations}

One-hundred and forty-six of the 1,774 study subjects (8.23\%) showed MSP-1(ICB910)-ELISA positivity. Yeoncheon presented the highest positive rate (Figure $1 \mathrm{C}$, 46/451, 10.20\%), followed by Paju (Figure 1B, 35/372, 9.41\%), Cheorwon (Figure 1D, 44/526, 8.37\%), and Gimpo (Figure 1A, 21/425, 4.94\%). The 2004 API was higher than the 2005 API. API did not vary within the same geographic location during the years 2004 and 2005 . Yeoncheon presented the highest API in both years, followed by Cheorwon, Paju and Gimpo. The seropositivity for the year 2004 showed a strong positive linear relationship with the APIs of 2004 and 2005 ( $r=0.691$ and $r=0.842$, respectively), but was statistically insignificant (Table 1).

\section{Local malaria transmission in Gimpo}

Twenty-one of the 425 inhabitants (4.94\%) presented a positive response in MSP-1(ICB910)-ELISA. Haseongmyeon presented the highest ELISA-positive rate (Figure 1a, $6 / 53,11.32 \%$ ), followed by Yangchonmyeon (Figure 1c, 10/206, 4.85\%) and Wolgotmyeon (Figure 1b, 5/166, $3.01 \%)$. Wolgotmyeon presented the highest API in 2004 (1.42) and 2005 (0.71). Haseongmyeon presented the second highest API in 2004 (0.69), but there were no new diagnoses in 2005. Yangchonmyeon was third in API in 2004 (0.50) and second in the year $2005(0.25)$. The seropositivity in 2004 showed a strong negative linear relationship with the APIs of the years 2004 and 2005 ( $\mathrm{r}=-0.513, \mathrm{r}=-0.887$, respectively). However, these correlations were not statistically significant (Table 2).

\section{Local malaria transmission in Paju}

Thirty-five of the 372 inhabitants (9.41\%) showed an ELISA-positive response. Musaneup had a higher positive rate (Figure 1e, 28/232, 12.07\%) than Papyeongmyeon (Figure 1d, 7/140, 5.00\%). Papyeongmyeon had a higher API than Munsaneup in the years 2004 and 2005. The seropositivity in 2004 showed a strong negative linear relationship with the APIs of 2004 and 2005 ( $\mathrm{r}=-1.000$ and $\mathrm{r}=-1.000$, respectively). This result was statistically significant ( $P=0.01$ for each year, Table 3 ).

\section{Local malaria transmission in Yeoncheon-gun}

Forty-six of the 451 inhabitants (10.20\%) of Yeoncheon-gun showed an ELISA-positive response. Misanmyeon had the highest positive rate (Figure 1h, 9/75, 12.00\%), followed by Baekhakmyeon (Figure 1f, 28/265, 10.57\%) and Wangjingmyeon (Figure 1g, 9/111, 8.11\%). Baekhakmyeon had the highest API in 2004 (3.69) and dropped to third place in 2005 (1.34). Misanmyeon had the second highest API in 2004 (2.79) and ranked first in 2005 (2.79). Wangjingmyeon had the lowest API in 2004 (1.60) and ranked second in 2005 (2.40). The seropositivity in 2004 showed a strong positive linear relationship with the API of 2004 ( $r=0.685)$ and a weak linear relationship with API of $2005(r=0.111)$. However, these results were statistically insignificant (Table 4).

\section{Local malaria transmission in Cheorwon}

Forty-four of the 526 inhabitants (8.37\%) of Cheorwon showed MSP-1(ICB910)-ELISA positivity. Cheorwoneup 


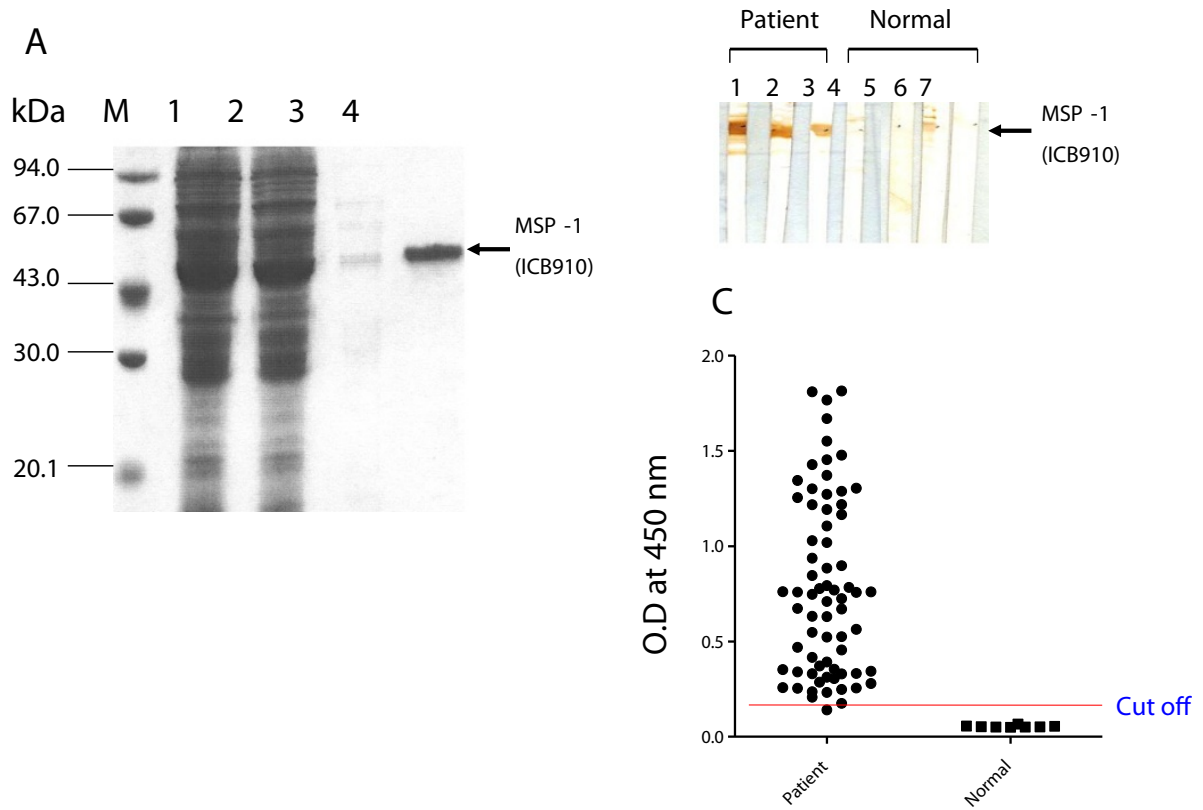

Figure 3 Characterization of recombinant merozoite surface protein-1 (ICB910). (A) Purification of recombinant MSP-1 (ICB910) by Ni-NTA agarose affinity chromatography. Lane M, molecular weight marker; lane 1, E. coli DH5a cell lysate after protein expression was induced with IPTG; lane 2, flow-through; lane 3, wash; lane 4, eluted fraction. (B) Western blot analysis of recombinant MSP-1(ICB910) protein. Lanes 1-3, samples from patients infected with malaria; Lanes 4-7, samples from uninfected individuals. (C) Immune responses of recombinant MSP-1(ICB910) to vivax malaria patient group and normal person by Enzyme linked immunosorbent assay.

presented the highest positive rate (Figure 1k, 17/142, $11.97 \%$ ), followed by Geunnammyeon (Figure 11, 15/143, 10.49\%), Gimhwaeup (Figure 1i, 12/115, 10.43\%) and Seomyeon (Figure 1j, 0/126, 0.00\%). Seomyeon had the highest API in 2004 (1.98), followed by Gimhwaeup (1.54), Cheorwoneup (0.86) and Geunnammyeon (0.45). However, Gimhwaeup had the highest API in 2005, followed by Geunnammyeon (2.23), Seomyeon (0.49) and Cheorwoneup (0.35). The seropositivity in 2004 showed a strong negative linear relationship with an API

Table 1 Rates of MSP-1(ICB910)-ELISA positivity and annual parasite incidence

\begin{tabular}{ccccccc}
\hline \multirow{2}{*}{ Area } & $\begin{array}{c}\text { No. of } \\
\text { sera tested }\end{array}$ & $\begin{array}{c}\text { No. of } \\
\text { positive sera }\end{array}$ & $\begin{array}{c}\text { Positive } \\
\text { rate (\%) }\end{array}$ & \multicolumn{2}{c}{ API $^{\mathbf{a}}$} \\
\hline Gimpo & 425 & 21 & 4.94 & 0.73 & $\mathbf{2 0 0 5}$ \\
Paju & 372 & 35 & 9.41 & 1.07 & 0.86 \\
Yeoncheon & 451 & 46 & 10.20 & 2.99 & 1.99 \\
Cheorwon & 526 & 44 & 8.37 & 1.13 & 1.20 \\
Total & 1774 & 146 & 8.23 & 1.48 & 1.08 \\
\hline
\end{tabular}

${ }^{\mathrm{a} A P I}$; Annual parasite incidence.

-Correlation coefficient between MSP-1(ICB910) positive rate of 2004 and API of 2004 ( $r=0.691, P=0.309$ ).

-Correlation coefficient between MSP-1(ICB910) positive rate of 2004 and API of 2005 ( $r=0.842, P=0.158)$. of $2004(\mathrm{r}=-0.762)$ and a strong positive linear relationship with API of $2005(r=0.430)$. However, these correlations were statistically insignificant (Table 5).

\section{Discussion}

The areas surveyed, Gimpo, Paju, Yeoncheon, and Cheorwon, which are located within $10-15 \mathrm{~km}$ of the southern DMZ, are part of re-emerging malarial outbreak areas in South Korea [8]. The DMZ is a $4 \mathrm{~km}$-wide and $250 \mathrm{~km}$-long corridor that extends across the middle part of the Korean peninsula. Natural landscape, ecosystems

Table 2 Rates of MSP-1(ICB910)-ELISA positivity and annual parasite incidence in Gimpo

\begin{tabular}{cccccc}
\hline \multirow{2}{*}{ Village } & $\begin{array}{c}\text { No. of } \\
\text { sera tested }\end{array}$ & $\begin{array}{c}\text { No. of } \\
\text { positive sera }\end{array}$ & $\begin{array}{c}\text { Positive } \\
\text { rate (\%) }\end{array}$ & \multicolumn{2}{c}{ API $^{\mathbf{a}}$} \\
\hline Haseongmyeon & 53 & 6 & 11.32 & $\mathbf{2 0 0 5}$ \\
Yangchonmyeon & 206 & 10 & 4.85 & 0.59 & 0.00 \\
Wolgotmyeon & 166 & 5 & 3.01 & 1.42 & 0.71 \\
Total & 425 & 21 & 4.94 & 0.87 & 0.49 \\
\hline
\end{tabular}

${ }^{\mathrm{a}} \mathrm{APl}$; Annual parasite incidence.

-Correlation coefficient between MSP-1 (ICB910) positive rate of 2004 and API of $2004(r=-0.513, P=0.657)$.

-Correlation coefficient between MSP-1 (ICB910) positive rate of 2004 and API of 2005 ( $r=-0.887, P=0.306)$. 
Table 3 Rates of MSP-1(ICB910)-ELISA positivity and annual parasite incidence in Paju

\begin{tabular}{ccccccc}
\hline \multirow{2}{*}{ Village } & \multirow{2}{*}{$\begin{array}{c}\text { No. of } \\
\text { sera tested }\end{array}$} & $\begin{array}{c}\text { No. of } \\
\text { positive sera }\end{array}$ & $\begin{array}{c}\text { Positive } \\
\text { rate (\%) }\end{array}$ & \multicolumn{2}{c}{$\mathbf{A P I}^{\mathbf{a}}$} \\
\hline Munsaneup & 232 & 28 & $\mathbf{2 0 0 4}$ & $\mathbf{2 0 0 5}$ \\
Papyeongmyeon & 140 & 7 & 5.00 & 1.00 & 0.82 \\
Total & 372 & 35 & 9.41 & 1.31 & 1.01 \\
\hline
\end{tabular}

${ }^{\mathrm{a} A P l}$; Annual parasite incidence.

-Correlation coefficient between MSP-1(ICB910) positive rate of 2004 and API of 2004 ( $r=-1.000, P=0.01)$.

-Correlation coefficient between MSP-1(ICB910) positive rate of 2004 and API of $2005(r=-1.000, P=0.01)$

and biodiversity are highly conserved in the DMZ [23]. The outbreak areas expanded yearly both in the southern and eastern directions from the DMZ in the initial stage of re-emergence. Although there has been a sharp decline in the reported cases in recent years, a re-emergence of malaria in these areas cannot be ruled out. Effective control programmes will prevent the re-emergence of malaria. Sensitive diagnostic tools that allow rapid and accurate diagnosis will ensure the effectiveness of malaria prevention and control programmes. MSP-1 is considered as a useful antigen for serodiagnosis and is an important vaccine candidate against asexual blood stages [24-27]. The MSP-1 protein binds to the surface of erythrocytes and is one of the merozoite surface ligands involved in the invasion of the erythrocytes. Comparison of the sequences of MSP-1 proteins from $P$. vivax, $P$. falciparum, and $P$. yoelii revealed seven ICBs (ICB1, ICB2, ICB4, ICB5, ICB6, ICB8, and ICB10) and three CBs (CB3, CB7 and CB9) [11]. The immune responses to the $\mathrm{N}$ - and $\mathrm{C}$-terminal regions of MSP-1 have been characterized [24]. The 11 regions of MSP-1 expressed in E. coli were glutathione S-transferase (GST) regions. It was reported that $83.3 \%$ of malaria patients had IgG complexes against at least one of the GST-fusion proteins. In addition, the frequency of patients with the IgG antibodies to recombinant ICB10 protein, which contained only the $111 \mathrm{C}$-terminal amino acids of MSP-1, increased with the number of $P$. vivax

Table 4 Rates of MSP-1(ICB910)-ELISA positivity and annual parasite incidence in Yeoncheon

\begin{tabular}{cccccc}
\hline Village & $\begin{array}{c}\text { No. of } \\
\text { sera tested }\end{array}$ & $\begin{array}{c}\text { No. of } \\
\text { positive sera }\end{array}$ & $\begin{array}{c}\text { Positive } \\
\text { rate (\%) }\end{array}$ & \multicolumn{2}{c}{ API $^{\mathbf{2}}$} \\
\hline Wangjingmyeon & 111 & 9 & 8.11 & $\mathbf{2 0 0 5}$ \\
Baekhakmyeon & 265 & 28 & 10.57 & 3.69 & 1.34 \\
Misanmyeon & 75 & 9 & 12.00 & 2.79 & 2.79 \\
Total & 451 & 46 & 10.20 & 2.69 & 2.18 \\
\hline
\end{tabular}

${ }^{a} A P I ;$ Annual parasite incidence.

-Correlation coefficient between MSP-1(ICB910) positive rate of 2004 and API of 2004 ( $r=0.685, P=0.519$ ).

-Correlation coefficient between MSP-1(ICB910) positive rate of 2004 and API of 2005 ( $r=0.111, P=0.929)$.
Table 5 Rates of MSP-1(ICB910)-ELISA positivity and annual parasite incidence in Cheorwon

\begin{tabular}{cccccc}
\hline \multirow{2}{*}{ Village } & \multirow{2}{*}{$\begin{array}{c}\text { No. of } \\
\text { sera tested }\end{array}$} & $\begin{array}{c}\text { No. of } \\
\text { positive sera }\end{array}$ & $\begin{array}{c}\text { Positive } \\
\text { rate (\%) }\end{array}$ & \multicolumn{2}{c}{$\mathbf{A P I}^{\mathbf{a}}$} \\
\hline Gimhwaeup & 115 & 12 & 10.43 & $\mathbf{2 0 0 5}$ \\
Seomyeon & 126 & 0 & 0.00 & 7.98 & 2.46 \\
Geunnammyeon & 143 & 15 & 10.49 & 0.45 & 2.23 \\
Cheorwoneup & 142 & 17 & 11.97 & 0.86 & 0.35 \\
Total & 526 & 44 & 8.37 & 1.21 & 1.38 \\
\hline
\end{tabular}

${ }^{\mathrm{a}} A P I ;$ Annual parasite incidence.

-Correlation coefficient between MSP-1(ICB910) positive rate of 2004 and API of 2004 ( $r=-0.762, P=0.238)$.

-Correlation coefficient between MSP-1(ICB910) positive rate of 2004 and API of 2005 ( $r=0.420, P=0.580)$.

malaria experiences, reaching $83.3 \%$ after four experiences. However, the responses to recombinant ICB2-5, which consisted of 506 C-terminal amino acids of MSP-1, did not have the same frequency. The titre of the antibody against recombinant ICB10 protein was greater than that of the antibody against recombinant ICB2-5. Furthermore, ICB10 helps peripheral blood mononuclear cells (PBMCs) to secrete IFN- $\gamma$, suggesting that T-cell epitopes are present in this region. Soares et al. found that the C-terminal region was immunogenic to both antibodies and T-cells were produced following infections in humans [28]. MSP-1 could be a useful vaccine against $P$. vivax malaria because the C-terminal region of MSP-1 is less polymorphic than the N-terminal region [29] and the epitopes to Band T-cells have specific humoral responses that produce longer-term stability [30]. Therefore, the region from CB9 to ICB10 of MSP-1 was selected and expressed as a recombinant protein in E. coli for use in sero-epidemiology. In the present study, a recombinant MSP-1(ICB910) antigen-based ELISA diagnostic method was used to evaluate the antibody levels in the inhabitants of high-risk areas. The incidence of malaria peaks in August after the rainy season and declines to baseline by mid-October. Therefore, blood sampling was carried out between lateOctober and mid-December, when the active anopheline population had diminished. Since ELISA-based screening for the presence of an antibody could provide useful information regarding $P$. vivax infection in a previously naïve population, the significance between the positive rate and incidence of malaria in high-risk areas were compared.

The MSP-1(ICB910)-ELISA-positive rates and the APIs of four cities in both years showed strong linear relationships, but were not statistically significant $(P=0.309$ and $P=0.158$, respectively) (Table 1 ). The local transmission in Gimpo showed a strong negative relationship between API and MSP-1(ICB910)-ELISA, but it was not significant (2004, $P=0.657 ; 2005, P=0.306$ ). Local transmission in Paju showed a strong negative relationship between API and MSP-1(ICB910)-ELISA that was statistically significant 
(2004, $P=0.01 ; 2005, P=0.01$ ). Local transmission in Yeoncheon showed strong relationship between the API and MSP-1(ICB910)-ELISA of 2004 and a weak relationship in 2005 (2004, $P=0.519 ; 2005, P=0.929)$. In Cheorwon, the MSP-1(ICB910)-ELISA response and API had a strong negative relationship in 2004 $(P=0.238)$ and a medium positive relationship in $2005(P=0.580)$. These differences might be related to the different malaria control programmes adopted in the areas. Malaria control programmes are administered by four public health centres (PHCs). Each PHC uses their own manual that takes the local malaria prevalence and geographical characteristics into account. While evaluating the malaria transmission in a given geographical region, factors such as temperature, mosquito density, vector capacity, climate, rainfall, and humidity must be considered [31]. However, collecting data requires much effort. Therefore, it is necessary to establish a cost-effective tool to analyse the current and future transmission of malaria in specific geographic areas using serodiagnostic methods. Parasitaemia provides a classical means for measuring malaria endemicity, but patient incidence alone is unlikely to provide a complete understanding of malaria prevalence. Factors including the population density of mosquitoes, vectorial capacity, long- to short-incubation patient ratio, symptomatic to asymptomatic patient ratio, differences in rainfall and temperature, and immunity of the community all affect malaria prevalence in Korea. These results suggest that antibody detection methods provide results that are more valuable than API values obtained by microscopic examination in certain circumstances. Such methods will help to better understand malaria transmission in a given geographical area.

\section{Conclusions}

The antibody detection method using MSP-1 (ICB910)ELISA provides useful information regarding malaria prevalence in specific geographical areas and individuals. This serological method is useful for identifying areas that require malaria control.

\section{Competing interests}

The authors declare that they have no competing interests.

\section{Authors' contributions \\ TSK, YJK and HWL conceived and designed the study, and contributed to the execution of the research. HWL and TSK wrote the manuscript. YS and YJK performed the statistical analysis. TSK, YS, YJK, WJL, BKN, and HWL collected blood samples. HWL purified the MSP-1(ICB910) recombinant protein. TSK, WIL and HWL performed MSP-1(ICB910)-ELISA and the diagnosis of malaria by microscopic examination. All authors have read and approved the final manuscript.}

\section{Acknowledgements}

We are grateful to all blood donors and the staff of the public health centres in Gimpo, Paju, Yeoncheon, and Cheorwon. This work was supported by an internal grant of the Korean National Institute of Health and Inha University Research Fund (2012).

\section{Author details}

'Department of Parasitology, College of Medicine, Inha University, Incheon 405-751, Republic of Korea. 'Department of Anatomy, College of Korean Medicine, Institute of Korean Medicine, Kyung Hee University,

Hoegi-dongDongdaemun-gu, Seoul 130-701, Republic of Korea. ${ }^{3}$ Division of Malaria and Parasitic Diseases, National Institute of Health, Korea Centers for Disease Control and Prevention, Osong 363-951, Republic of Korea. ${ }^{4}$ Department of Parasitology and Institute of Health Sciences, Gyeongsang National University School of Medicine, Jinju 660-751, Korea. ${ }^{5}$ Department of Biomedical Science, Jungwon University, Goesan, Chungbuk 367-805, Republic of Korea. ${ }^{6}$ Department of Pathology, Immunology, and Laboratory Medicine, College of Medicine, University of Florida, Florida, FL 32610, USA.

Received: 13 March 2014 Accepted: 3 August 2014

Published: 12 August 2014

\section{References}

1. Mendis K, Sina BJ, Marchesini P, Carter R: The neglected burden of Plasmodium vivax malaria. Am J Trop Med Hyg 2001, 64:97-106.

2. Hasegawa: Malaria in Korea. Chosen lgakkai Zasshi 1913, 4:53-69.

3. National Malaria Eradication Service, Ministry of Health and Social Affairs, ROK: Malaria pre-Eradication Programme in Korea, 1961-1965, Progress report. ; 1966:44-70. in Korean.

4. Paik YH, Rhee HI, Shim JC: Malaria in Korea. Jpn J Exp Med 1988, 58:55-66.

5. Soh CT, Lee KT, Im Kl, Min DY, Ahn MH, Kim JJ, Yong TS: Current status of malaria in Korea. Yonsei Rep Trop Med 1985, 16:11-18.

6. Chai IH, Lim Gl, Yoon SN, Oh WI, Kim SJ, Chai JY: Occurrence of tertian malaria in a male patient who has never been abroad. Korean J Parasitol 1994, 32:195-200 (in Korean).

7. Cho SY, Kong Y, Park SM, Lee JS, Lim YA, Chae SL, Kho WG, Lee JS, Shim JC, Shin HK: Two vivax malaria cases detected in Korea. Korean J Parasitol 1994, 32:281-284.

8. Lee JS, Kho WG, Lee HW, Seo M, Lee WJ: Current status of vivax malaria among civilians in Korea. Korean J Parasitol 1998, 36:241-248.

9. Kim TS, Kim JS, Na BK, Lee WJ, Kim HC, Youn SK, Gwack J, Kim HS, Cho P, Ahn SK, Cha SH, Park YK, Lee SK, Kang YJ, Sohn Y, Hong Y, Lee HW: Decreasing incidence of Plasmodium vivax in the Republic of Korea during 2010-2012. Malar J 2013, 12:309.

10. Engers HD, Godal T: Malaria vaccine development; current status. Parasit Today 1983, 14:56-64.

11. del Portillo HA, Longacre S, Khouri E, David PH: Primary structure of the merozoite surface antigen 1 of Plasmodium vivax reveals sequences conserved between different Plasmodium species. Proc Natl Acad Sci U S A 1991, 88:4030-4034.

12. Cerutti C Jr, Boulos M, Coutinho AF, Hatab MC, Falqueto A, Rezende HR, Duarte AM, Collins W, Malafronte RS: Epidemiologic aspects of the malaria transmission cycle in an area of very low incidence in Brazil. Malar J 2007, 6:33.

13. Collins EC, Skinner JC: The indirect fluorescent antibody test for malaria. Am J Trop Med Hyg 1972, 121:690-695.

14. Wang DQ, Tang LH, Gu ZC, Zheng X, Yang MN: Application of the indirect fluorescent antibody assay in the study of malaria infection in the Yangtze River Three Gorges Reservoir. China Malar J 2009, 8:199.

15. Moody A: Rapid diagnostic tests for malaria parasites. Clin Microbiol Rev 2002, 15:66-78.

16. McKenzie FE, Prudhomme WA, Magill AJ, Forney JR, Permpanich B, Lucas C, Gasser RA Jr, Wongsrichanalai C: White blood cell counts and malaria. $J$ Infect Dis 2005, 192:323-330.

17. Na BK, Lee HW, Moon SU, In TS, Lin K, Maung M, Chung GT, Lee JK, Kim TS, Kong $Y$ : Genetic variations of the dihydrofolate reductase gene of Plasmodium vivax in Mandalay Division, Myanmar. Parasitol Res 2005, 96:321-325.

18. Lee HW, Lee WJ, Lee JS, Lee HS: DNA sequencing and expression of the Circumsporozoite protein of Plasmodium vivax Korean isolate in Escherichia coli. Korean J Microbiol 1999, 37:234-242.

19. Lim KJ, Park JW, Sohn MJ, Lee S, Oh JH, Kim HC, Bahk YY, Kim YS: A direct sandwich ELISA to detect antibodies against the C-terminal region of merozoite surface protein 1 could be a useful diagnostic method to identify Plasmodium vivax exposed persons. Parasitol Res 2002, 88:855-860 
20. Tsang VCW, Peralta JM, Simons AR: Enzyme-linked immunoelectrotransfer blot techniques (EITB) for studying the specificities of antigens and antibodies separated by gel electrophoresis. Meth Enzymol 1983, 92:377-391.

21. Gao YH, Li HL, Lu Y, Gao FM, Lin YH, Zhou HC, Zhang LH, Wang H: Identification of a vaccine candidate antigen, PfMAg-1, from Plasmodium falciparum with monoclonal antibody M26-32. Parasitol Res 2009, 105:1723-1732.

22. Cohen J: Statistical Power Analysis for the Behavioral Sciences. 2nd edition. Hillsdale, NJ, USA: Psychology Press; 1988.

23. Kim KC: Preserving biodiversity in Korea's demilitarized zone. Science 1997, 278:242-243.

24. Kaslow DC, Kumar S: Expression and immunogenicity of the C-terminus of a major blood-stage surface protein of Plasmodium vivax, Pv200(19), secreted from Saccharomyces cerevisiae. Immunol Lett 1996, 51:187-189.

25. Dutta S, Ware LA, Barbosa A, Ockenhouse CF, Lanar DE: Purification, characterization, and immunogenicity of a disulfide cross-linked Plasmodium vivax vaccine candidate antigen, merozoite surface protein 1, expressed in Escherichia coli. Infect Immun 2001, 69:5464-5470.

26. Dutta S, Kaushal DC, Ware LA, Puri SK, Kaushal NA, Narula A, Upadhyaya DS, Lanar DE: Merozoite surface protein 1 of Plasmodium vivax induces a protective response against Plasmodium cynomolgi challenge in rhesus monkeys. Infect Immun 2005, 73:5936-5944.

27. Sachdeva S, Ahmad G, Malhotra P, Mukherjee P, Chauhan VS: Comparison of immunogencities of recombinant Plasmodium vivax merozoite surface protein 1 19- and 42-kiloDalton fragments expressed in Escherichia coli. Infect Immun 2004, 72:5775-5782.

28. Soares IS, Levitus G, Souza JM, del Portillo HA, Rodrigues MM: Acquired immune responses to the $\mathrm{N}$ - and $\mathrm{C}$-terminal regions of Plasmodium vivax merozoite surface protein 1 in individuals exposed to malaria. Infect Immun 1997, 65:1606-1614.

29. Pasay MC, Cheng Q, Rzepczyk C, Saul A: Dimorphism of the $C$ terminus of the Plasmodium vivax merozoite surface protein 1. Mol Biochem Parasitol 1995, 70:217-219.

30. Shi YP, Sayed U, Qari SH, Roberts JM, Udhayakumar V, Oloo AJ, Hawley WA, Kaslow DC, Nahlen BL, Lal AA: Natural immune response to the C-terminal 19-kilodalton domain of Plasmodium falciparum merozoite surface protein 1. Infect Immun 1996, 67:2716-2723.

31. Snow RW, Gilles HM: The Anopheles vector. In Essential Malariology. 4th edition. Edited by Warrell DA, Gilles HM. London: Arnold; 2002:59-84.

doi:10.1186/1475-2875-13-311

Cite this article as: Kim et al:: Detection of antibodies against the CB9 to ICB10 region of merozoite surface protein-1 of Plasmodium vivax among the inhabitants in epidemic areas. Malaria Journal 2014 13:311.

\section{Submit your next manuscript to BioMed Central and take full advantage of:}

- Convenient online submission

- Thorough peer review

- No space constraints or color figure charges

- Immediate publication on acceptance

- Inclusion in PubMed, CAS, Scopus and Google Scholar

- Research which is freely available for redistribution 